\title{
Nutrients flow from runoff at burned forest site
} in Lake Tahoe Basin

\author{
by W. Wally Miller, Dale W. Johnson, \\ Theresa M. Loupe, James S. Sedinger, \\ Erin M. Carroll, James D. Murphy, \\ Roger F. Walker and Dallas Glass
}

The long-term trend toward decreased water clarity in Lake Tahoe is well documented, and is strongly linked to increased nitrogen and phosphorus loading from surrounding watersheds. Recent research has detected very high concentrations of biologically available nitrogen and phosphorus in overland/litter interflow from Sierra ecosystems. The objective of this study was to assess the effect of a localized wildfire on the nutrient content of such runoff. The wildfire increased the frequency and magnitude of elevated nutrient concentrations in discharge runoff for all three parameters studied (nitrate nitrogen, ammonium nitrogen and phosphate phosphorus). Although the mobilization of nutrients was increased due to wildfire, the lack of $O$ horizon material (the surface organic layers of mineral soils) after burning may ultimately reduce discharge concentrations over time.

The long-term trend toward de1 creased water clarity in Lake Tahoe is well documented, and is strongly linked to increased nitrogen and phosphorus loading (Goldman 1989; Goldman et al. 1990; Jassby et al. 1999) (see page 49). If we are to arrest further deterioration of the lake's famed clarity, it is essential to recognize that its water quality is directly linked to upland watershed processes, including nutrient cycling, groundwater and stream flow, surface runoff, precipitation type (rain vs. snow, intensity and duration), atmospheric deposition and anthropogenic manipulation (such as

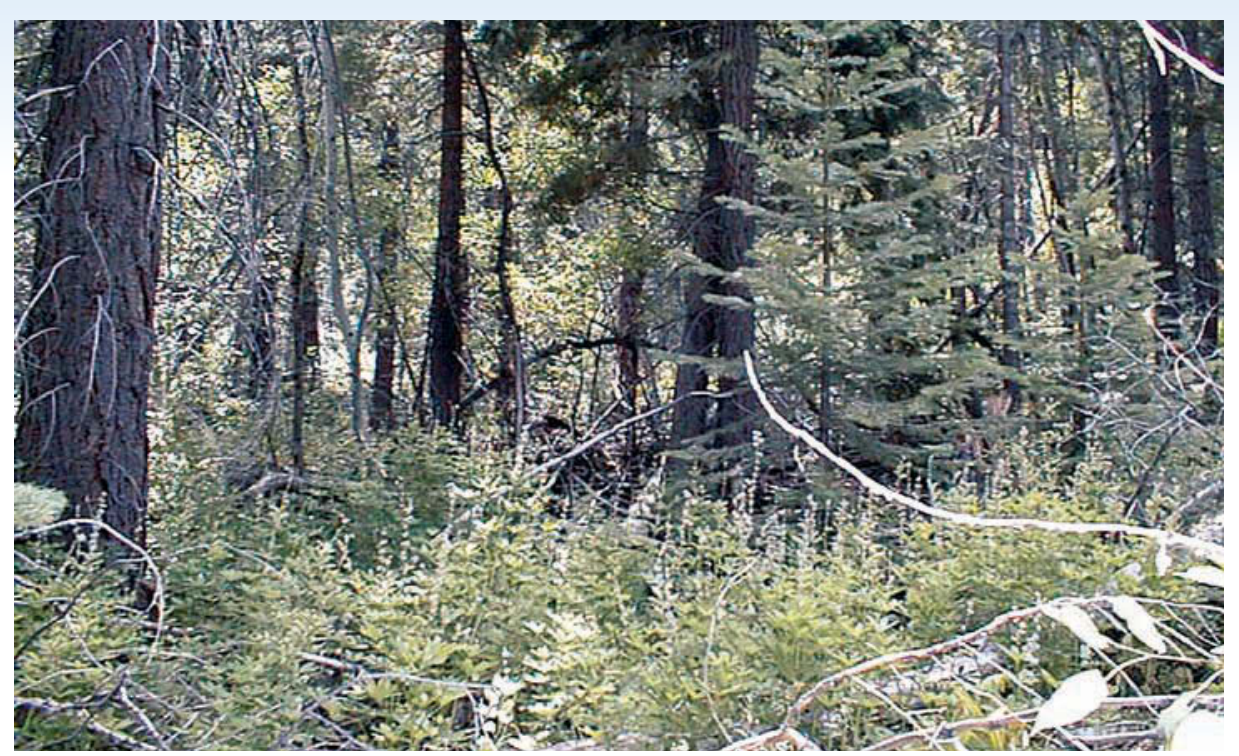

Fire suppression and the lack of forest thinning have led to dense, overgrown forests throughout the Sierra Nevada and Lake Tahoe Basin.

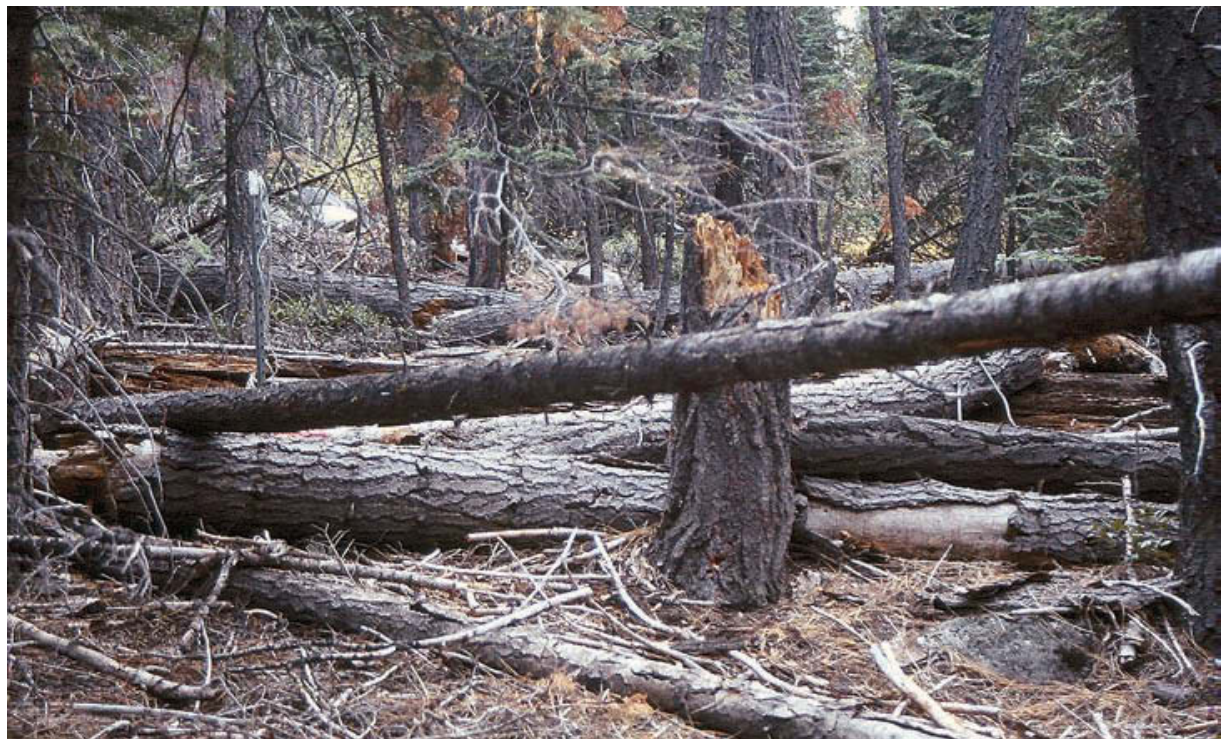

Although highly variable across the stand, downed and dead fuel loading now commonly exceeds 616,000 pounds per acre in some locations.

fire and fire suppression) (Reuter and Miller 2000).

Fire suppression, in particular, has caused a decline in overall forest health due to the buildup of high tree densities and heavily vegetated understory; ladder fuels, which provide vertical continuity between surface fuels and crown fuels in a forest stand; downed timber fuels; and deepened forest floor, particularly the thickened $\mathrm{O}$ horizon (surface organic layers of mineral soils). It is a commonplace belief throughout the Tahoe Basin and Sierra Nevada that forests long protected by fire suppression contribute little in the way of natural nutrient discharge, because nutrient uptake and interception are maximized by the thick understory accumulation (Reuter and Miller 2000).

Nonetheless, recent Sierra research has detected very high concentrations of biologically available nutrients in the overland/litter interflow taking place above the mineral surface at the interface between surface deposits of decomposing organic litter and the underlying, often water-repellent, mineral soil surface (Miller et al. 2005). 


\section{GLOSSARY}

Biologically available: That portion of a chemical compound or element that can be readily taken up by living organisms.

Discharge flux: The time rate of transport of a quantity (e.g., mass or volume of a fluid) across a given area (volume flow per unit time per unit area).

Litter/mineral surface interface: The boundary between surface deposits of decomposing litter materials ( $\mathrm{O}$ horizon) and the underlying mineral soil surface (A horizon).

Mineralization: The conversion of organic nutrients to inorganic compounds. This process is typically accomplished by various soil microbes but may also be induced by fire. Once mineralized, such nutrients are present in soluble inorganic form and subject to biotic uptake, infiltration and leaching, and/or runoff discharge.

Nutrient: Elements or compounds essential as raw materials for organism growth and development, such as nitrogen and phosphorus, that are often present in soluble inorganic forms such as nitrate nitrogen, ammonium nitrogen and phosphate phosphorus.

Nutrient concentration and loading: Concentration is the amount of a given nutrient per unit of solution, whereas loading is an absolute amount. Both are used as indicators of water quality degradation, but the absolute amount of pollution is often considered more important.

Nutrient cycling: The circulation or exchange of elements, such as nitrogen, phosphorus and carbon dioxide, between nonliving (e.g., the soil) and living (e.g., plants, microorganisms) portions of the environment. The process includes all inputs such as wet and dry atmospheric deposition, plant litter fall and decay; internal cycles such as mineralization and plant uptake; outputs such as leaching, volatilization and runoff discharge; and biotic (biomass incorporation) and abiotic (soil) storage.

Nutrient, labile: Soluble inorganic nutrient forms such as nitrate, ammonium nitrogen and phosphate phosphorus, that are readily transformed by microorganisms, readily available to plants and easily transported by water flow.

Overland flow/litter interflow: Overland flow is runoff water moving across the land surface; litter interflow is runoff water moving within surface deposits of organic litter above the organic/mineral soil interface.

Soil profile and horizonation: The soil profile is a vertical sequence of welldefined layers of soil, sediment or decaying vegetation; soil horizons are layers of organic or mineral materials lying approximately parallel to the land surface with physical, chemical and biological properties that are distinct from the adjacent layers. Soil horizon designations include the $\mathrm{O}$ horizon (layers dominated by organic materials), A horizon (mineral layers that formed at the land surface or are located immediately below the O horizon), B horizon (the mineral subsurface horizon formed and lying below the A horizon) and $C$ horizon (subsurface mineral horizons, excluding bedrock, that are little affected by pedogenic soilforming processes).

The nutrients found by Miller et al. (2005) at high concentrations included: nitrate nitrogen $\left(\mathrm{NO}_{3}{ }^{-} \mathrm{N}\right)$ at up to 95.4 milligrams nitrogen per liter (ppm), ammonium nitrogen $\left(\mathrm{NH}_{4}{ }^{+}-\mathrm{N}\right)$ at up to 87.2 milligrams nitrogen per liter (ppm); and phosphate phosphorus $\left(\mathrm{PO}_{4}^{3-}-\mathrm{P}\right)$ at up to 24.4 milligrams phosphorus per liter (ppm). These levels suggest that the nutrient ions in runoff must be derived from the well-developed surface organic layers in fire-suppressed forests. Also, it suggests that there has been little contact between the organically derived nutri- ents and the underlying mineral soil surface - where ammonium nitrogen and phosphate phosphorus would normally be removed from solution by direct interaction with soil particles - thereby reducing soluble discharge concentrations.

The buildup of fuels in the understory has also increased the potential for catastrophic wildfires, and wildfire certainly affects the various nutrient pools available for waterborne transport. The objective of this study was to assess the effect of a localized wildfire on the nutrient content of surface runoff.
A wildfire clearly has the potential to cause an immediate adverse impact on discharge water quality.

\section{Wildfire provides opportunity}

Location and setting. The study location was a 29.6-acre (12-hectare) parcel located 1.24 miles (2 kilometers) southeast of the south shore of Lake Tahoe, near Stateline, Nev. ( $57^{\circ} 30^{\prime}$ latitude and $119^{\circ} 55^{\prime}$ longitude). The vegetation was overgrown, and the dominant overstory consisted of decadent (trees deteriorating due to age) white fir (Abies concolor Gord. \& Glend.), Jeffrey pine (Pinus jeffreyi Grev. $\&$ Balf.) and lesser amounts of sugar pine (Pinus lambertiana Dougl. [Strobus L. Mold.]). The understory was dominated by Sierra chinquapin (Chrysolepis sempervirens [Kellogg] Hjelmq), currant (Ribes spp.) and minor amounts of snow bush (Ceanothus velutinis Dougl. Ex Hook.) and bitterbrush (Purshia tridentata [Pursh] DC). The soils developed on granitic parent material and belong to the Cagwin-rock outcrop complex found on predominantly north-facing slopes of $10 \%$ to $40 \%$. Total average annual precipitation (1984 to 2004) across the basin is about 31.9 inches ( 81 centimeters) (TIIMS 2005).

Plots. Sixteen 0.10-acre (0.04-hectare) study plots were established in 2001 for a study originally designed and instrumented to examine the effects of mechanical harvest and prescribed fire, and their interaction (two-by-two-by-four replications) with forest health, nutrient cycling and discharge water quality. On July 3, 2002, the Gondola wildfire altered the study by fully burning seven (nos. 10 to 16) of the 16 previously established research plots and partially burning two more (nos. 8 and, very minimally, 9). We were thus given the seldom-afforded opportunity to study post-wildfire effects on nutrient discharge in runoff, compared to that from adjacent unburned controls (fig. 1).

Runoff collectors. Runoff collectors (Miller et al. 2005) had been installed in four plots (nos. 1 to 3 , and no. 14) prior to the wildfire (September and 


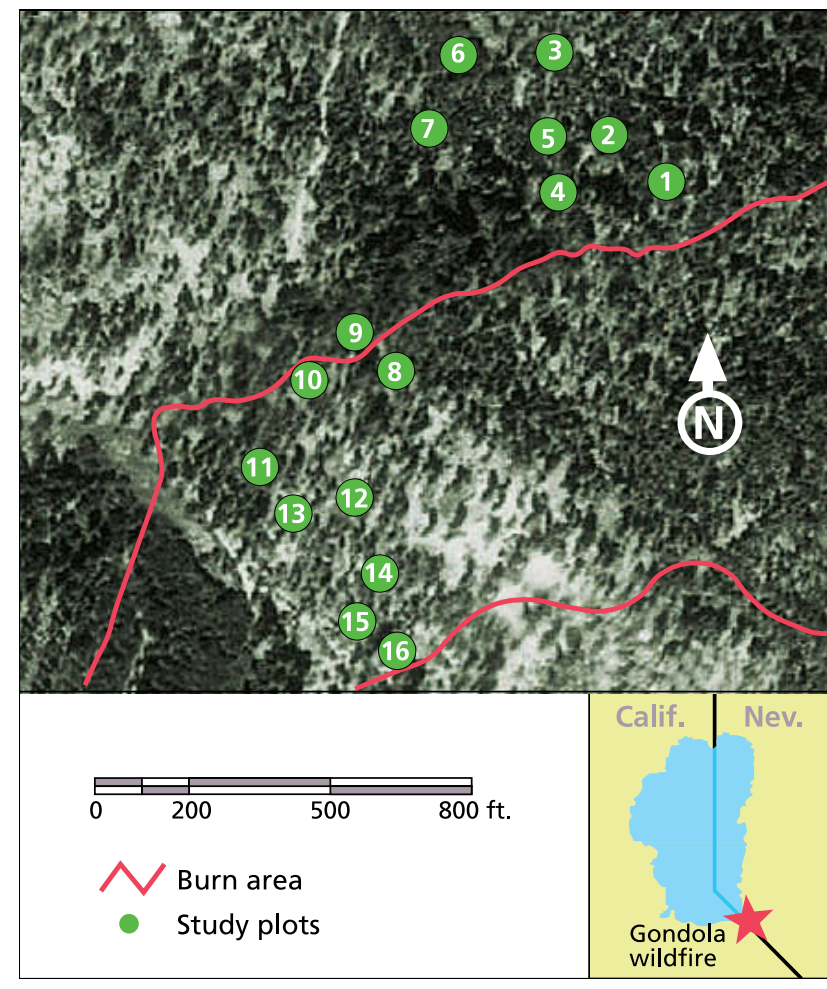

Fig. 1. The study site and Gondola wildfire location.

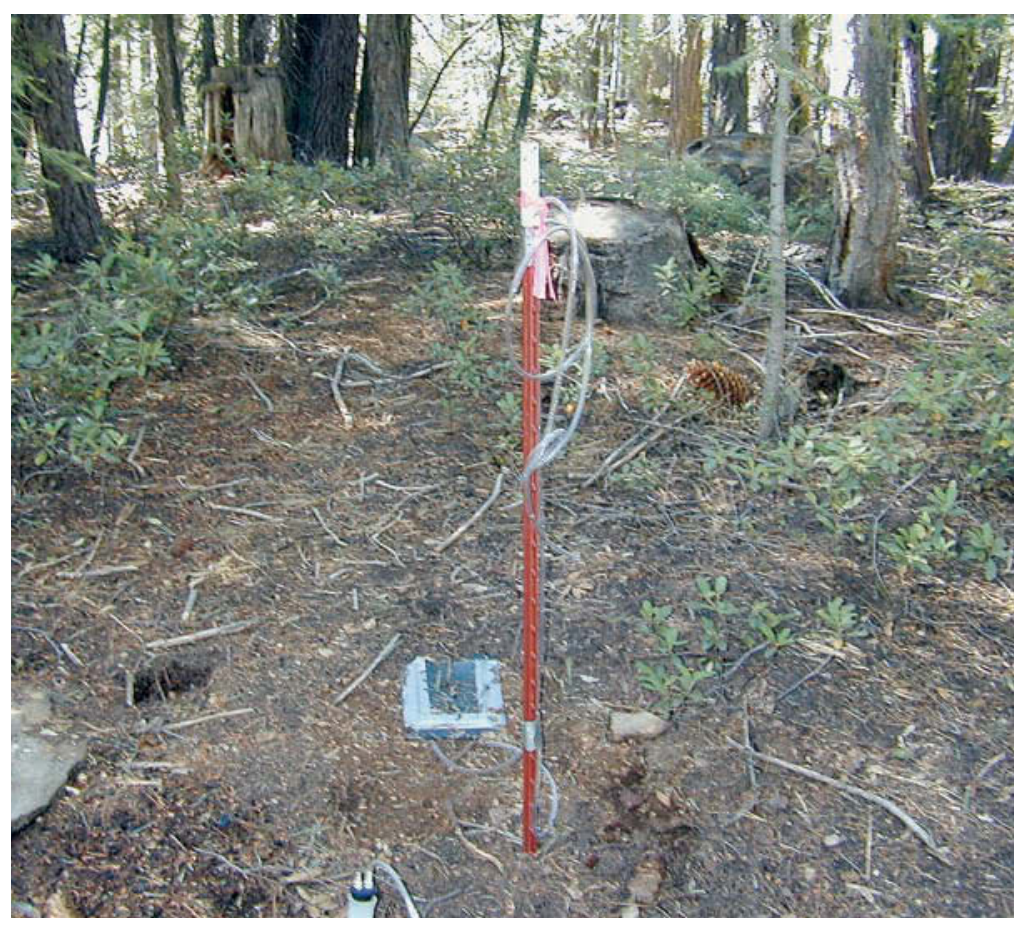

Data from runoff collectors, above, shows that runoff from overland/litter interflow seeps downslope through the organic surface layers during rainfall and snowmelt, never gaining enough momentum to cause physical disturbance.
November 2001), and were reinstalled in each of the 16 plots about 4 weeks after the burn once access to the site was allowed. They consisted of a buried bucket container slightly larger than 2 gallons (8 liters) fitted with a collection funnel, vent-stack roof flashing, screen and high-density polyethylene cover (fig. 2). The top of the collection funnel was located approximately 2 inches ( 5 centimeters) below the soil surface, and the roof flashing was aligned perpendicular to the slope either at the soil surface of the bare or burned soil for the collection of overland flow, or at the litter/mineral soil interface for the collection of litter interflow.

Incidental runoff. Construction of the collectors was such that incidental runoff could be generated on the impermeable surface of the collector itself over a 0.39-inch-by-3.54-inches (1-by-9 centimeters) flow path (1.4 square inches; 9 square centimeters). Incidental runoff is derived from sources other than natural processes of overland/litter interflow; for example, the impermeable surface of the runoff collector itself. For an average annual precipitation of 31.9 inches (81 centimeters), this would result in a maximum of 730 milliliters of incidental runoff. Direct vertical infiltration of precipitation into the 0.07 -square-inch (0.43-square-centimeter) V-notch opening itself could account for another 35 milliliters, for a total of about 770 milliliters per year of incidental runoff not attributable to natural processes. For cumulative collections far exceeding 770 milliliters per year, we can think of no explanation other than that of in situ overland flow/litter interflow in the form of surface runoff.

Data collection. For purposes of data comparison, plot no. 9 was grouped with the unburned treatments and plot no. 8 with the burned treatments. The runoff collectors were checked twice monthly during the winter and spring months (December through April) when access was possible, and following each rainfall event during the summer and fall (May through November). When present, runoff from overland flow or litter interflow was retrieved from the collection containers using a Model Change C pump (Soil Moisture Corp.). Total volume was measured and a subsample was retained for chemical analyses. The subsamples were filtered through a $1.8 \times 10^{-5}$-inch $(0.45 \mu \mathrm{m})$ filter (Osmonics Laboratory Products) and analyzed at the Soil, Water and Forage Analytical Laboratory of Oklahoma

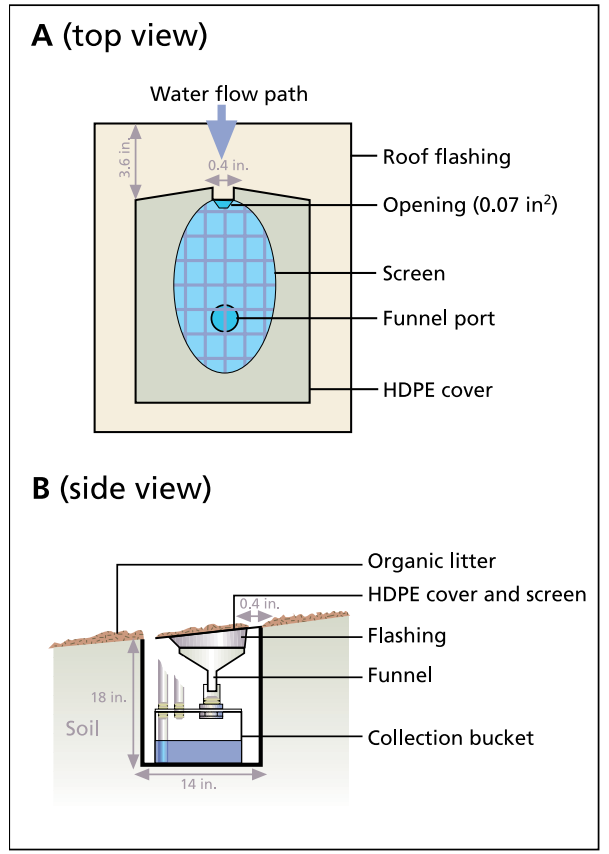

Fig. 2. Runoff collectors were developed to test the premise that natural overland flow from heavily forested ecosystems is an unimportant source of water and nutrient discharge from upland Sierra forests. Source: Miller et al. 2005. 


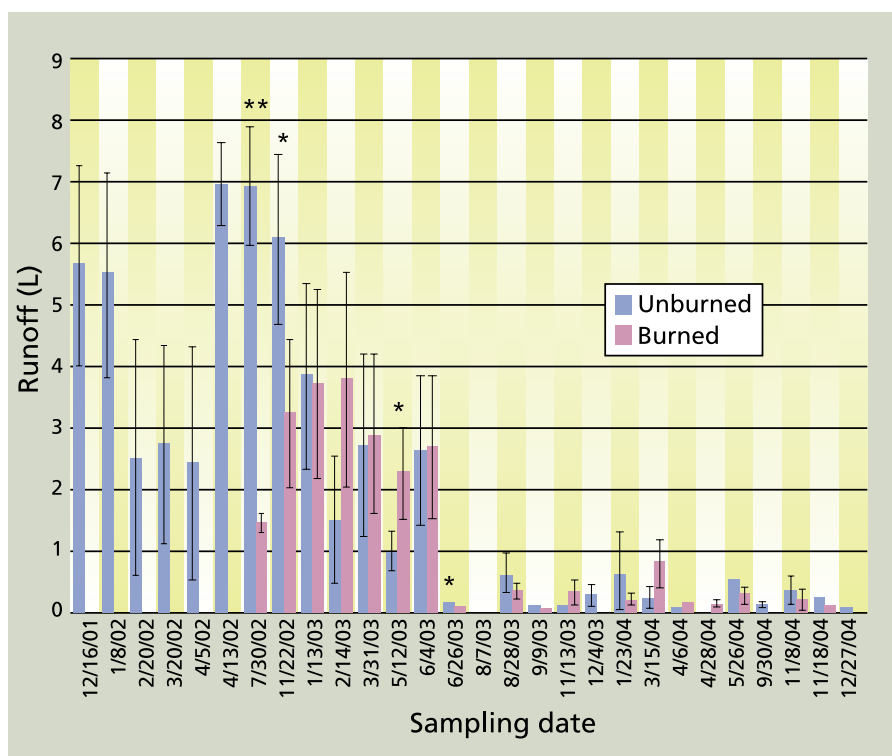

Fig. 3. Mean runoff collected from burned and unburned study plots; the Gondola fire was July 3, 2002. Error bars are for standard error; $t$-test significance differences are noted as $P<0.10\left(^{*}\right)$ or $P<0.05\left(^{(*)}\right.$ $(1,000$ milliliters $[\mathrm{mL}]=1.0$ liter $=0.265$ gallon $)$.

State University (Stillwater, Okla.). The nutrients were analyzed on a Lachat flow-injection analyzer using the salicylate method for ammonium nitrogen (SSSA 1996), the cadmium reduction method for nitrate nitrogen (US EPA 1979) and the ascorbic acid method for phosphate phosphorus (US EPA 1979).

Data analysis. We were unable to collect samples from each plot on every sampling occasion because of periodic soil-water repellency, the erratic weather patterns over the study area and unavoidable field damage from animals. Consequently, a mixed models analysis was performed on the postwildfire data only. Our design included fixed plots, randomly placed within the burned and unburned areas ( $\mathrm{n}=8$ plots in each area). Because each plot was sampled repeatedly during the study, we treated plots as repeated random effects in the analysis. Treatment was a fixed effect (burned versus unburned). Samples were classified as being from winter (December through April) or summer (May through November), so we included season as a second fixed effect. We included the volume of runoff as a continuous covariate.

Hypotheses for each dependent variable (ammonium nitrogen, nitrate nitrogen and phosphate phosphorus) were then analyzed separately using a mixed models procedure, with plots as the random effect, treatment and season as fixed effects, and runoff volume as a covariate. We considered previously conceived combinations of the fixed and random effects and the covariate as potential hypotheses to explain patterns in the dependent variables. The only interaction we considered was that between treatment and season.

Models were analyzed using PROC MIXED in SAS (SAS Institute 2004).

\section{Runoff and nutrient mobilization}

We measured the mean interflow runoff from four unburned plots (nos. 1 to 3 , and no. 14) prior to the July 3 , 2002, wildfire and eight unburned plots (nos. 1 to 7 , and no. 9) following the wildfire, and overland flow runoff from eight burned plots (no. 8, and nos. 10 to 16) (fig. 3). The total (not per sampling event) amount of collector-derived incidental runoff over the 36-month period following the wildfire - from July 30, 2002, to Dec. 27,2004 , - could account for only about 0.61 gallon (2.31 liters; 2,310 milliliters) of the cumulative runoff measured. Therefore, cumulative values greater than 2.31 liters were attributed to on-site, natural overland or litter interflow.

Variability was high because runoff was not present in every collector at each sampling date. However, $t$-test comparison of the overall data (not presented) showed runoff volumes to be significantly greater $(P<0.05)$ during the winter and spring (December to April), compared to summer and fall collections (May to November). This trend is typical of Sierra ecosystems.

The first two samplings following the wildfire (one during a summer rain event, July 30, 2002, and another in fall, Nov. 22, 2005) showed significantly less runoff from the burned plots. In the unburned areas, water repellency is typically found at the litter/soil surface interface boundary (Bashir 1969), is most pronounced during late summer and early fall (July and August, October and November) and diminishes over winter (Burcar et al. 1994). Lower initial runoff from the burned area may have been due to the fire-induced development of a 2-inch (5-centimeter) layer of wettable soil above a subsurface waterrepellent layer in the burned areas. This effect has been reported in the literature (DeBano 1969), and is caused by intense heat that volatilizes the organic coatings on the mineral surfaces, which then recondense with depth. Once the wettable layer has saturated (such as during snowmelt) one would expect at least comparable runoff from the burned areas. This was generally the case, with few significant differences observed between treatments thereafter.

The concentrations of nutrients in the surface runoff for the unburned and burned plots following the wildfire were also highly variable (fig. $4 \mathrm{~A}-\mathrm{C}$ ). $T$-test analysis showed that the only consistently significant $(P<0.05)$ treatment (unburned / burned) effect was for phosphate phosphorus, where concentrations in the surface runoff were greater from the burned areas the first year following the wildfire (fig. 4A). Although not significant for either of the nitrogen forms because of the variability among individual plots over time, the trend was similar in that both ammonium and nitrate nitrogen concentrations in the runoff from burned plots were generally higher than from the unburned controls (figs. 4B and 4C).

The nutrient concentrations that we found were much greater (two to three orders of magnitude) than those typically reported for Tahoe Basin tributaries and the lake itself (Reuter and Miller 
Heavy surface accumulations of decomposing layered organic deposits, right, are now predominant in the Tahoe Basin and can be as high as 83,000 pounds per acre in some areas.

2000; Miller et al. 2005). Furthermore, visual comparison of the data suggests that there is a seasonal trend to periods of elevated nutrient discharge, with the highest concentrations typically associated with runoff collected during the summer months. For example, runoff volumes were at times significantly lower in the summer (hence a concentration effect) compared to the larger amounts collected during winter precipitation and snowmelt (December through April). This apparent seasonal trend in nutrient discharge concentrations remained following the wildfire; but compared to the unburned controls, the effect of wildfire appears to have increased the frequency and magnitude of elevated summertime nutrient discharge concentrations for all three parameters, at least during the first season following the wildfire event.

\section{Evaluating observational results}

We used an information theoretic approach to assess hypotheses about the roles of fixed effects, random effects and covariates in explaining variations in the dependent variables (Burnham and Anderson 2002). Briefly, this approach simultaneously considers multiple competing hypotheses and evaluates the weight of evidence supporting each. The method relies on the use of Akaike's information criterion (AIC), described by: $\mathrm{AIC}=-2 \times 1 \mathrm{n}(\mathrm{L})+2 \mathrm{~K}$; $\mathrm{K}$ is the number of parameters in the statistical model and $\mathrm{L}$ is the likelihood for the model (estimated by PROC MIXED). We then used model weights (which indicate the probability that a given model is the best among a set of models considered), to estimate the strength of evidence supporting a particular model. Parameter estimates (such as differences between treatments) and their confidence intervals were used to indicate the strength of the effects we considered (such as burn effects). This approach is increasingly being applied in ecological studies and is considered the most appropriate for evaluating hypotheses in observational studies such as ours (Burnham and Anderson 2002).
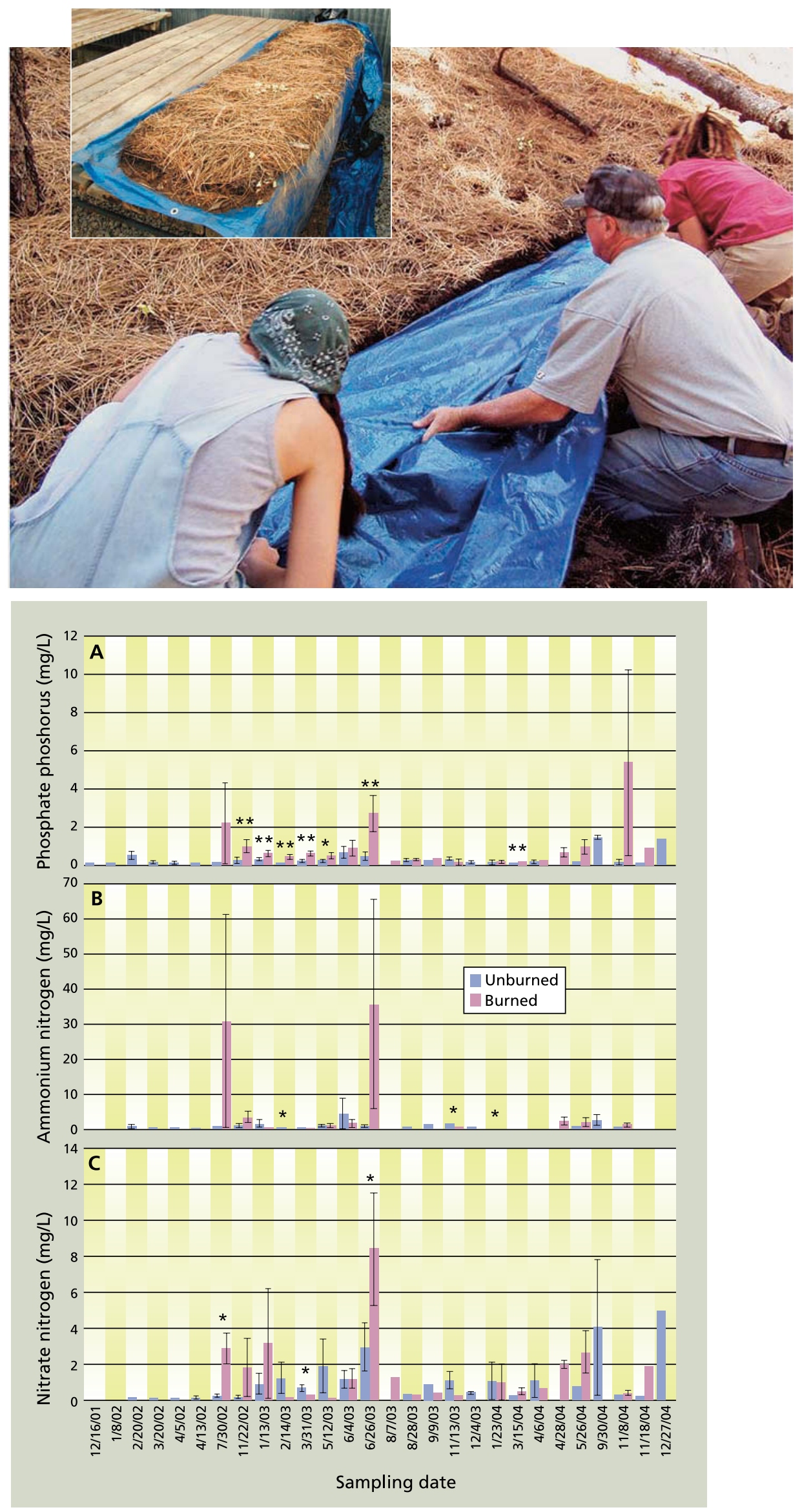

Fig. 4. Mean (A) phosphate phosphorus, (B) ammonium nitrogen and (C) nitrate nitrogen concentrations in runoff from burned and unburned plots; the Gondola fire was July 3 , 2002. Error bars are for standard error, and significance differences are noted as $P<0.10$ $\left.{ }^{*}\right)$ or $P<0.05\left(^{* *}\right.$ (milligrams [mg] per liter $=8.3 \times 10^{-6}$ pounds per gallon). 
Parameter estimates for the treatment-only model were significant for runoff concentrations of phosphate phosphorus $(P<0.05)$ and to a lesser extent nitrate nitrogen $(P<0.10)$, but not ammonium nitrogen. For the season-only model, parameter estimates were significant for runoff concentrations of phosphate phosphorus $(P<0.05)$ and to a lesser extent ammonium nitrogen $(P<0.10)$, but not for nitrate nitrogen. For example, mean runoff concentrations of phosphate phosphorus were $0.51 \pm 0.22$ milligrams of phosphorus per liter (ppm) lower from unburned compared to burned areas, and $0.46 \pm 0.21$ milligrams of phosphorus per liter (ppm) lower in winter compared to summer runoff.

The sum of AIC weights for a given model parameter is indicative of the overall importance of that parameter in explaining variation in the dependent variable (Burnham and Anderson 2002) (table 1). For phosphate phosphorus, model weights indicated that the relative importance of treatment was about $87 \%$, compared to $65 \%$ for season and $43 \%$ for runoff volume. For ammonium nitrogen, the relative importance of treatment and season were comparable at $65 \%$ and $61 \%$, respectively, while the effect of runoff volume was not as well supported ( $38 \%$ of model weight). The pattern was somewhat different for nitrate nitrogen in that runoff volume (91\% of model weight) was the most important predictor, followed by treatment (60\% of model weight) and season (48\% of model weight). This may be related to the fact that, unlike the other ions, nitrate nitrogen is not adsorbed to the mineral fraction of soils and is therefore more strongly affected by solution dynamics. In any case, wildfire clearly appears to affect the concentrations of nutrients in runoff discharge through enhanced mobilization, likely the result of temperature-induced mineralization.

\section{A worst-case scenario?}

There is now evidence in many Sierra watersheds that fire suppression has resulted in a heavy buildup of a nutrientrich forest floor (approximately 83,228 pounds per acre $[93,200$ kilograms per hectare]) (Murphy et al. 2006), and that slow leaching and runoff of this nutrientrich material can be a significant longterm source of biologically available nitrogen and phosphorus (Loupe 2005). In the pre-fire suppression era, the organic mat was thinner, and the equilibrium for annual nutrient mineralization and discharge flux was also lower. On the other hand, the post-fire suppression era has resulted in the excessive buildup of much-thicker, nutrient-rich organic residues in heavily forested watersheds; in turn, there has been less nutrient volatilization and external dispersion. Although the litter mass is certainly a major sink for total nutrients, the mineralized nutrient content also increases proportionately in fire-suppressed forests. At our study location, the equi- librium has apparently shifted so that the annual amount of internal nutrient cycling increased, causing the organic mass to release more available nutrients into solutions passing through it (Loupe 2005).

Wildfire seems to further increase the immediate mobilization of labile nutrients (nutrients readily available to microorganisms and plants), and at least some of this labile nitrogen and phosphorus may well make it off-site during precipitation or snowmelt. The magnitude of such discharge cannot be quantified at this time because we have no means of determining the volume flow on an areawide basis. While wildfire causes a dramatic increase in nutrient mobilization, we have not found the same effect with cooler-

\begin{tabular}{|c|c|c|c|c|c|}
\hline $\begin{array}{l}\text { Dependent } \\
\text { variable }\end{array}$ & $\begin{array}{l}\text { Predictive } \\
\text { modelt }\end{array}$ & $\begin{array}{l}\text { Delta } \\
\text { AIC }\end{array}$ & $\begin{array}{c}\text { AIC } \\
\text { weight }\end{array}$ & $\begin{array}{l}\text { Parameters } \\
\text { estimated }\end{array}$ & $\begin{array}{c}-2 \text { log } \\
\text { likelihood }\end{array}$ \\
\hline \multicolumn{6}{|c|}{ Phosphate phosphorus $\left(\mathrm{PO}_{4}{ }^{3-}-\mathrm{P}\right)$} \\
\hline & $\mathrm{T}$ & 0 & 0.190 & 4 & 486.7 \\
\hline & $\mathrm{T}, \mathrm{S}$ & 0.3 & 0.164 & 6 & 495.2 \\
\hline & $\mathrm{T}, \mathrm{S}, \mathrm{T} \times \mathrm{S}$ & 0.4 & 0.156 & 7 & 480.6 \\
\hline & $\mathrm{T}, \mathrm{V}$ & 0.6 & 0.141 & 5 & 485.1 \\
\hline & $\mathrm{T}, \mathrm{S}, \mathrm{T} \times \mathrm{S}, \mathrm{V}$ & 1.1 & 0.110 & 8 & 479.1 \\
\hline & $\mathrm{T}, \mathrm{S}, \mathrm{V}$ & 1.2 & 0.104 & 7 & 481.4 \\
\hline & $\mathrm{S}$ & 2.2 & 0.063 & 5 & 486.7 \\
\hline & S, V & 2.6 & 0.052 & 6 & 485.0 \\
\hline & V & 4.5 & 0.020 & 5 & 489.1 \\
\hline \multicolumn{6}{|c|}{ Ammonium nitrogen $\left(\mathrm{NH}_{4}^{+}-\mathrm{N}\right)$} \\
\hline & $\mathrm{S}$ & 0 & 0.179 & 3 & $1,409.9$ \\
\hline & $\mathrm{T}, \mathrm{S}$ & 0.1 & 0.170 & 4 & $1,407.9$ \\
\hline & $\mathrm{T}$ & 0.4 & 0.146 & 3 & $1,410.3$ \\
\hline & $\mathrm{T}, \mathrm{S}, \mathrm{T} \times \mathrm{S}$ & 0.7 & 0.126 & 5 & $1,406.4$ \\
\hline & $\mathrm{S}, \mathrm{V}$ & 1.4 & 0.089 & 4 & $1,409.2$ \\
\hline & $\mathrm{T}, \mathrm{V}$ & 1.6 & 0.080 & 4 & $1,409.5$ \\
\hline & V & 1.6 & 0.080 & 3 & $1,411.6$ \\
\hline & $\mathrm{T}, \mathrm{S}, \mathrm{V}$ & 1.7 & 0.076 & 5 & $1,407.5$ \\
\hline & $\mathrm{T}, \mathrm{S}, \mathrm{T} \times \mathrm{S}, \mathrm{V}$ & 2.4 & 0.054 & 6 & $1,405.9$ \\
\hline \multicolumn{6}{|c|}{ Nitrate nitrogen $\left(\mathrm{NO}_{3}-\mathrm{N}\right)$} \\
\hline & $\mathrm{T}, \mathrm{V}$ & 0 & 0.263 & 6 & 854.8 \\
\hline & V & 0.2 & 0.238 & 5 & 857.1 \\
\hline & $\mathrm{T}, \mathrm{S}, \mathrm{V}$ & 1.3 & 0.138 & 7 & 853.9 \\
\hline & $\mathrm{T}, \mathrm{S}, \mathrm{T} \times \mathrm{S}, \mathrm{V}$ & 1.3 & 0.138 & 7 & 853.9 \\
\hline & S, V & 1.4 & 0.131 & 6 & 856.2 \\
\hline & $\mathrm{T}, \mathrm{S}$ & 3.9 & 0.037 & 5 & 860.9 \\
\hline & $S$ & 4.5 & 0.028 & 4 & 863.6 \\
\hline & $\mathrm{T}$ & 5.8 & 0.014 & 5 & 862.8 \\
\hline & $\mathrm{T}, \mathrm{S}, \mathrm{T} \times \mathrm{S}$ & 6.1 & 0.012 & 6 & 860.9 \\
\hline \multicolumn{6}{|c|}{$\begin{array}{l}\text { * Information theoretic approaches (AIC) were used to compare and evaluate models. Delta AIC represents the difference } \\
\text { in AIC between the best model considered and other models. AIC weight indicates the probability that a particular } \\
\text { model was best among those considered. Model hierarchy for each dependent variable is presented in descending order } \\
\text { of best-to-least fit model. }\end{array}$} \\
\hline \multicolumn{6}{|c|}{$\begin{array}{l}+T=\text { treatment, } S=\text { season, } V=\text { runoff volume and } T \times S=\text { treatment-by-season interaction. The sum of AIC weights for a } \\
\text { given model parameter is indicative of its overall importance to model estimation of the dependent variable. }\end{array}$} \\
\hline
\end{tabular}




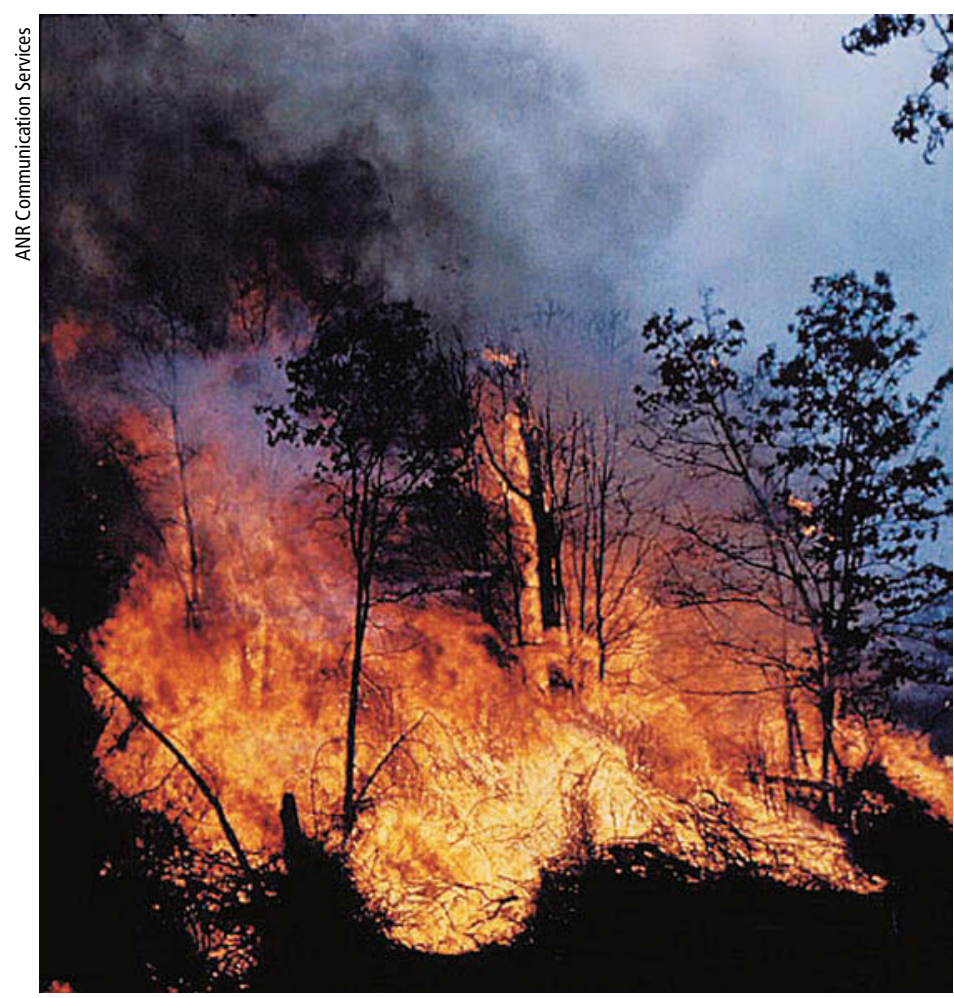

Wildfires appear to mobilize nutrients, which may then run off during rainfall. However, periodic burning helps to reduce nutrient levels in unnaturally heavy deposits of organic materials on the forest floor, thereby improving water quality in the long term.

burning, more-mosaic, prescribed fires (work in progress). Fuel reduction due to fire may cause an immediate increase in the surface mobility of nutrients, but the long-term effect may be a decrease in nutrient discharges due to the reduction in its source, the heavy surface deposits of decomposing organic litter.

\section{Adaptive management implications}

From an adaptive management standpoint, the question has been raised as to whether it is better to do nothing and risk a wildfire-induced "shock treatment" effect on nutrient discharge, or is it better to embark on a fuels reduction program (either mechanical or prescribed fire) with the ultimate objective of returning to a more natural fire regime characteristic of the pre-fire suppression era? We do not yet have the complete answer to this question, but are now beginning to understand the issues.

Fire suppression in forested watersheds has caused a decline in forest health (Johnson et al. 2005; Murphy et al. 2006; Neary et al. 1999) partially resulting in the heavy buildup of organic debris. This excess organic debris has apparently become a substantial source of biologically available nitrogen and phosphorus, which at least has the potential to move off-site into adjacent waterways (Loupe 2005). Doing nothing will certainly not help to alleviate the current problem of declining lake clarity. A wildfire clearly has the potential to cause an immediate adverse impact on discharge water quality. But the longterm effect of wildfires may be to improve water quality, because the lack of heavy surface deposits of decomposing organic materials after burning should ultimately reduce nutrient discharge concentrations over time. The best strategy is most likely some form of fuel reduction - such as mechanical harvest and/or prescribed fire - to lower the wildfire potential and at the same time reduce the current buildup and leaching of thick, nutrient rich, surface deposits of organic materials.

W.W. Miller, D.W. Johnson, J.S. Sedinger and R.F. Walker are Professors; T.M. Loupe and D. Glass are Graduate Students, Inter-Disciplinary Hydrologic Sciences Program; E.M. Carroll is Graduate Student, Natural Resources and Environmental Science; and J.D. Murphy is Graduate, Hydrologic Sciences Program (now with the Nevada Department of Transportation, Carson City, Nev.); all within the Department of Natural Resources and Environmental Science, College of Agriculture, Biotechnology, and Natural Resources, University of Nevada, Reno. This research was supported in part by the Nevada Agricultural Experiment Station (Pub. no. 52042973). We gratefully acknowledge contribu- tions from the U.S. Forest Service Lake Tahoe Basin Management Unit and Joint Fire Sciences Program.

\section{References}

Bashir SM. 1969. Hydrophobic soils on the east side of Sierra Nevada. MS thesis. University of Nevada, Reno.

Burcar SW, Miller WW, Tyler SW, Johnson DW. 1994. Seasonal preferential flow in two Sierra Nevada soils under forested and meadow cover. SSSA J 58:1555-61.

Burnham KP, Anderson DR. 2002. Model Selection and Multimodel Inference: A Practical Information-

Theoretic Approach (2nd ed.). New York: SpringerVerlag. 488 p.

DeBano LF. 1969. The relationship between heat treatment and water repellency in soils. In: DeBano LF, Letey J (eds.). Water-Repellent Soils. Proc Symp on Water-Repellent Soils, May 6-10, UC Riverside, CA. p 265-79.

Goldman CR. 1989. Lake Tahoe: Preserving a fragile ecosystem. Environment 31:6-11, 27-31.

Goldman CR, Jassby AD, de Amezaga E. 1990 Forest fires, atmospheric deposition and primary productivity at Lake Tahoe, California-Nevada. Internationale Vereinigung fur Theoretische und Angewandte Limnologie. Verhandlungen 24:1489-96.

Jassby AD, Goldman CR, Reuter JE, Richards RC. 1999. Origins and scale dependence of temporal variability in the clarity of Lake Tahoe, California-Nevada. Limnol Oceanogr 44:282-94.

Johnson DW, Murphy JD, Susfalk RB, et al. 2005. The effects of wildfire, salvage logging, and post-fire $N$ fixation on the nutrient budgets of a Sierra forest. Forest Ecol Manage 220:155-65.

Loupe TM. 2005. The influence of forest litter and biomass reduction on the discharge of inorganic N, P, and S. MS Thesis. Hydrologic Sciences Program, Department of Natural Resources and Environmental Science, College of Agriculture, Biotechnology, and Natural Resources, University of Nevada, Reno, NV. 92 p.

Miller WW, Johnson DW, Denton C, et al. 2005. Inconspicuous nutrient laden surface runoff from mature forest Sierra watersheds. J Water Air Soil Pollution 163:3-17.

Murphy JD, Johnson DW, Miller WW, et al. 2006. Wildfire effects on soil nutrients and leaching in a Tahoe Basin watershed. J Environ Quality. In press.

Neary DG, Klopatek JM, DeBano LF, Folliot PF. 1999. Fire effects on belowground sustainability: A review and synthesis. Forest Ecol Manage 122:51-71.

Reuter JE, Miller WW. 2000. Aquatic resources, water quality and limnology of Lake Tahoe and its upland watershed. In: Murphy DD, Knopp CM (eds.). The Lake Tahoe Watershed Assessment: Vols. 1 and 2. USDA Forest Service Pacific Southwest Research Station, Gen Tech Rep PSW-GTR-178/176. p 215-402 (ch 4).

SAS Institute. 2004. SAS Version 9.1.3. Cary, NC.

[SSSA] Soil Science Society of America. 1996. Methods of Soil Analysis, Part 3 - Chemical Methods. SSSA \#5, SSSA and Amer Soc of Agron, Madison, WI.

[TIIMS] Tahoe Integrated Information Management Systems. 2005. Meteorology. http://www.tiims.org/Content/BasinTopics/meteorology/default.asp (viewed on May 17, 2005).

[US EPA] Environmental Protection Agency. 1979. Methods for Chemical Analysis of Water and Wastes. Office of Research and Development, Cincinnati, $\mathrm{OH}$. EPA-600/4-79-020. 